\title{
LAS ELECCIONES Y EL SISTEMA POLÍTICO*
}

\author{
José Antonio Aguilar Rivera \\ Centro de Investigación y Docencia Económicas
}

$\mathrm{H}$

asta hace poco tiempo, no había una historia bien documentada de las elecciones en México. Las elecciones, artefactos políticos e institucionales, son a la vez viejos y modernos. Constituyen un aspecto central del sistema político. Sin embargo, el papel que desempeñan en él ha sido dinámico. ¿Cómo se estudiaron las elecciones y el sistema político en Historia Mexicana (en adelante $H M$ ) al paso de los años?1

En Latinoamérica el interés retrospectivo en las elecciones ha sido el producto de la democratización que varios países han experimentado a partir de la década de los noventa. La relevancia que los procesos electorales adquirieron cuando éstos transitaron a la democracia hizo que el pasado, lleno de elecciones, se volviera interesante y se comenzó a cuestionar el entendimiento del fenómeno electoral que por décadas prevaleció y que postulaba que desde el siglo xix las elecciones no fueron, como se asumía formalmente, el mecanismo de transferencia del poder.

* El autor agradece a Óscar Uriel Ávila Velasco y a Julio César González Moreno su ayuda en la investigación de este ensayo.

${ }^{1}$ En este texto sólo se consideran artículos. No se incluyen reseñas de libros publicadas en la revista. 
En efecto, durante mucho tiempo los estudiosos vieron a las elecciones -pasadas y presentes- como accesorias a las cuestiones verdaderamente importantes o como ejemplos de arreglos meramente "formales" que encubrían relaciones sociales de dominación. Por ejemplo, en 1985 Gustavo Emmerich describió los "regímenes electorales" decimonónicos como asunto de las "clases dominantes". De acuerdo con Emmerich sólo "hacendados, magistrados, funcionarios públicos, profesionistas y comerciantes votaban, nadie más". ${ }^{2}$

Los años del autoritarismo posrevolucionario imprimieron en la mirada histórica una clara impronta. El pasado debió ser como el presente. Así, se concibió una continuidad entre las formas pasadas y las actuales de imponer el poder. Las elecciones eran sólo un componente más de la maquinaria autoritaria. No es sorprendente que en $H M$ haya pocos artículos dedicados a las elecciones antes del siglo XxI. Por ejemplo, en 1974 Lorenzo Meyer escribió un texto en el cual analizaba la evolución del estado mexicano como la lucha por adquirir el monopolio legítimo de la violencia. En aspectos claves -aunque no en todos- los hombres que heredaron el aparato revolucionario lograron ese monopolio. Durante el periodo posterior de consolidación autoritaria,

La oposición electoral siguió siendo tan estéril como en el pasado. En algunos momentos parte de la élite dirigente se separó del núcleo central y se presentó como disidente; tal fue el caso de Ezequiel Padilla en 1946 y Miguel Henríquez Guzmán en 1952. Oficialmente perdieron la elección por amplio margen y nada quedó de su oposición. Los pequeños partidos de oposición permanentes -PAN, PPS, PNM, PARM- sobrevivieron en buena medida porque se comportaron como loyal opposition; su presencia legitimó la hegemonía del PRI en la medida en que se dio la apariencia de un

2 Emmerich, “Las elecciones en México, 1808-1911”, p. 62. 
sistema pluripartidista pero sin afectar su contendido autoritario. Solo el pan, que desde una posición más o menos conservadora pide el cumplimiento efectivo de ciertos preceptos constitucionales, ha logrado crear una base electoral de cierta importancia en las zonas urbanas así como en los dos extremos geográficos del país. Sin embargo, ha sido impotente para evitar que en determinados momentos se anulen o alteren votaciones ganadas por él. ${ }^{3}$

La conclusión era clara: la división de poderes de la "teoría clásica de la democracia liberal” no operaba en la práctica. La élite política funcionaba como el árbitro entre los diversos grupos organizados que actuaban en el sistema político. Sin embargo, el poder obtenido por el sector empresarial, a resultas del proceso de desarrollo económico, le confirió un poder de veto a las decisiones del Estado.

En otro artículo, escrito siete años después en $H M$, Meyer analizó las elecciones presidenciales entre 1911 y $1940 .{ }^{4} \mathrm{El}$ autor reconocía que no era muy útil realizar un análisis cuantitativo "muy riguroso" de las elecciones mexicanas, pues

[...] no tendría el significado que se le puede atribuir en los sistemas pluripartidistas clásicos, puesto que las cifras rara vez reflejaron la realidad del sufragio. Fenómenos tales como la abstención, la manipulación de votos por parte de las autoridades, y en general la ausencia de una tradición democrática, llevan a que los resultados cuantitativos de las elecciones reflejen mal los fenómenos cualitativos y sustanciales de la vida política mexicana. El fraude electoral fue una constante del periodo, pues de lo contrario no es posible explicarse, entre otras cosas, votaciones estatales en las cuales el candidato oficial recibió el $100 \%$ de los votos. ${ }^{5}$

3 Meyer, “El Estado mexicano contemporáneo” (92), 1974, pp. 722-752, esp. pp. 747-748.

4 Meyer, “La Revolución Mexicana y sus elecciones” (126), 1982, pp. 143-197.

5 Meyer, “La Revolución Mexicana y sus elecciones” (126), 1982, p. 144. 
Sin embargo, Meyer afirmaba que las elecciones y su estudio en "sistemas 'no-clásicos' como el mexicano" no carecían de sentido. Se reconocía que el "ritual electoral" era un elemento que legitimaba el régimen interna y externamente. De la misma manera, las campañas políticas obligaban a los futuros gobernantes, "incluso en sistemas autoritarios, a definir acciones pasadas y metas futuras en términos ideológicos y por tanto generales, lo que al menos por un momento los fuerza a abandonar el pragmatismo cotidiano y a asumir compromisos". Finalmente, las elecciones presidenciales desataban las fuerzas internas del grupo gobernante. Esa liberación llevaba a la recomposición de los equilibrios internos y favorecía la circulación de élites. La verdadera lucha por el poder tenía lugar dentro del grupo gobernante y "no en la confrontación electoral con una oposición siempre en desventaja y generalmente débil". ${ }^{6}$

El papel de las elecciones a nivel subnacional fue explorado por Diana Juanicó en 1987. En el artículo "Partidos, facciones políticas y elecciones: Tlaxcala en 1924", la autora trató de explicar la singular dinámica partidista estatal a principios de los años veinte en ese estado. ${ }^{7}$ Mientras que a comienzos de la década dominaban a nivel nacional el Partido Laborista Mexicano y el Partido Nacional Agrarista en Tlaxcala, la fuerza de más peso era el Partido Liberal Constitucionalista, que para 1922 había prácticamente desaparecido a nivel nacional. La autora consideraba que las "cuestiones electorales" eran una punta de lanza para los estudios regionales. Aunque las contiendas políticas no se resolvieran en las urnas, el estudio de las coyunturas electorales ayudaba a entender las dinámicas de poder. Servían para medir la correlación de fuerzas entre los grupos locales y para determinar la posición del gobierno central frente a los conflictos regionales. Este uso se puede observar en

\footnotetext{
${ }^{6}$ MeYer, "La Revolución Mexicana y sus elecciones” (126), 1982, p. 145.

7 Juanicó, "Partidos, facciones políticas y elecciones" (145), 1987, pp. 75-100.
} 
el análisis de la política tlaxcalteca. Ahí, se observó que "la naturaleza legitimadora que las elecciones le daban al sistema se originaba más en el voto en sí mismo que en los resultados específicos de la contienda". Las elecciones para gobernador de 1924 ilustran con claridad la coyuntura política que vivía la entidad, "las fuerzas en pugna y su desempeño". A raíz del proceso electoral se evidenciaron las complejas dinámicas entre los grupos de poder locales y el centro. En esas elecciones, "observamos a un personal público "moderno", cuyo patrimonio político lo construyen a partir del dominio del aparato estatal, desde el cual ventajosamente negocian con las demás fuerzas en pugna. No hay organizaciones de masas; no hay coaliciones con milicias populares". Un grupo dirigente hizo suyo y usó como herramienta política a un partido político: el Liberal Constitucionalista Tlaxcalteca. Hay que resaltar que lo electoral aquí es claramente secundario: un medio para medir y explorar otros fenómenos políticos que se consideran de mayor importancia.

\section{MÁS ALLÁ DEL AUTORITARISMO}

En América Latina la década de quiebre con el antiguo paradigma sobre el significado de las elecciones puede situarse en los años noventa. Un libro marcó el incipiente interés en las elecciones: Historia de las elecciones en Iberoamérica, siglo XIX, editado por Antonio Annino en $1995 .{ }^{8}$ Son los años de construcción democrática. No en el caso de México, que tardó una década más en establecer plenamente la democracia electoral. Sin embargo, cuando eventualmente las elecciones comenzaron a verse con nuevos ojos, la mirada se concentró en el registro más lejano: el siglo xIx. La revaloración de las elecciones del periodo posrevolucionario ha recibido, en general, mucho menos atención.

8 Annino (coord.), Historia de las elecciones. 
A partir del milenio la historia electoral ha cobrado un gran interés y nuevas publicaciones han ampliado el horizonte de manera significativa. En 2016 Fausta Gantús, por ejemplo, coordinó la colección Elecciones en el México del siglo XIX, ${ }^{9}$ la cual se enfoca en el análisis de fuentes historiográficas hasta hace poco olvidadas, como los archivos municipales y estatales, así como en el replanteamiento del propósito de fuentes viejas, como los intercambios epistolares y la prensa, para el estudio de las elecciones decimonónicas. En esta obra Gantús cuestiona el lugar común de que las elecciones del siglo xix eran irrelevantes. Para Gantús, los preceptos historiográficos llevaron a especialistas a afirmar que

[...] en los comicios mexicanos habían dominado la violencia, la imposición, el ausentismo y la indiferencia; que no había habido ejercicio de la ciudadanía; que se carecía de partidos y de competencia electoral y que los resultados de los comicios habían estado siempre determinados de antemano, en fin, que se creía que no había existido tradición electoral en el México del siglo xIx”.

Gantús deja claro que estas preconcepciones son tal cosa; no realidades: "en realidad, muy poco se sabía entonces acerca de la historia de las elecciones, en especial de sus prácticas y de sus significados. ${ }^{10}$

En otra obra anterior, coordinada por Gantús y Alicia Salmerón, se revisó el papel de la prensa en la vida electoral del siglo XIX. ${ }^{11}$ Proponen que prensa y elecciones eran dos ámbitos estrechamente ligados de la vida política decimonónica, pues era en la prensa donde "se postulaban candidatos, se construían

${ }^{9}$ Gantús (coord.), Elecciones en el México del siglo XIX y Elecciones en el México del siglo XIX: las prácticas.

10 GanTús, Elecciones en el México del siglo XIX: las fuentes, pp. 11-12.

11 Gantús y Salmerón (coords.), Prensa y elecciones. 
campañas, se defendían y atacaban causas y personas". ${ }^{12}$ En otro libro, también coordinado por ambas investigadoras, se comparan los avances en la historia electoral mexicana decimonónica con progresos similares en otros países latinoamericanos. ${ }^{13} \mathrm{En}$ su introducción, Israel Arroyo señala cinco características principales de la nueva historiografía hispanoamericana sobre las elecciones decimonónicas: 1) un alejamiento de los caudillos y los caciques como entes monolíticos y un acercamiento a la manera contenciosa en que se conforma el poder local; 2) un alejamiento del modelo presentista e idealizado de la democracia; 3) la ponderación del fraude electoral, es decir el fin de la concepción de que todas las elecciones eran fraudulentas; 4) el acercamiento al constitucionalismo como indispensable para la comprensión del liberalismo decimonónico, y 5) la aproximación a lo local y a actores políticos más pequeños, como partidos, ayuntamientos, comunidades indígenas y pueblos. ${ }^{14}$

Otros trabajos relevantes sobre las elecciones en el México del siglo xIX son el volumen coordinado por Georgette José, el libro de Leticia Reina y la obra colectiva Las elecciones y el gobierno representativo en México. ${ }^{15} \mathrm{El}$ primero es un recuento histórico de la evolución de los sistemas electorales en México, de la República Restaurada a la alternancia. Los autores analizan en el volumen distintos elementos de los procesos electorales, como los candidatos, los partidos y las plataformas electorales, así como su relación con las constituciones y legislación electoral vigentes. ${ }^{16}$ El libro de Reina utiliza los conflictos electorales

12 Gantús y Salmerón (coords.), Prensa y elecciones, p. 15.

13 Gantús y Salmerón (coords.), Contribución a un diálogo.

${ }^{14}$ Arroyo, "Introducción: giros latinoamericanos y la nueva agenda académica sobre el siglo XIX”, en GANTÚs y SALMERón (coords.), Contribución a un diálogo, pp. 17-19.

15 José (coord.), Candidatos, campañas y elecciones; ReInA, Cultura política; Aguilar Rivera (coord.), Las elecciones y el gobierno.

16 José, Candidatos, campañas y elecciones, pp. 14-15. 
para aproximarse a las "prácticas ciudadanas" de los pueblos y las comunidades indígenas en el siglo xIX. En particular, Reina demuestra que los indígenas conformaron una "cultura política híbrida" que conjuntaba-clandestinamente-formas antiguas de elegir autoridades con la normatividad electoral oficial. Más aún, prueba que las comunidades indígenas y rurales no se mantuvieron al margen de la vía electoral, sino que recurrieron a ella para solucionar conflictos locales. Los indígenas y las comunidades rurales vieron en las urnas una manera de ejercer sus derechos ciudadanos y, más aún, de comunicar a los gobernantes la "voluntad del pueblo". ${ }^{17}$

Los artículos en $H M$ dedicados a las elecciones son muy escasos y ninguno de ellos se publicó en los años noventa. Como se afirmó, la democracia no había llegado aún, a pesar de que en 1997 se produjo por primera vez el fenómeno de gobierno dividido. Esto obligó a politólogos e historiadores a interrogar el pasado. Una muestra de ello fue el libro Gobernar sin mayoría. México 1867-1997 editado por María Amparo Casar e Ignacio Marván en 2002.18

En México la alternancia en la presidencia tuvo lugar en el año 2000. Por fin, las elecciones sirvieron para cambiar la autoridad máxima en el país. La instalación de la normalidad democrática a inicios de siglo le dio un innegable impulso a la historia revisionista. En 2001 Melchor Campos García publicó en HM el artículo "Faccionalismo y votaciones en Yucatán, 1824-1832". ${ }^{19}$ El texto estudia el declive de la legitimidad de los procedimientos electorales al comienzo de la república federal. Muy pronto el conflicto faccional hizo prensa en la joven república. Las elecciones fueron el campo de batalla de facciones como las logias masónicas. La autoridad de las elecciones para ordenar

\footnotetext{
17 ReIna, Cultura política, pp. 17-19.

18 Casar y Marván (coords.), Gobernar sin mayoría.

19 Campos García, “Faccionalismo y votaciones en Yucatán” (201), 2001, pp. 59-102.
} 
la transferencia de poder fue minada muy pronto, cuando al final del primer periodo presidencial el procedimiento de sucesión fue subvertido. En Yucatán, el grupo político dominante logró sostenerse "mediante el control de las votaciones hasta su derrocamiento en noviembre de 1829 por el golpe militar de Campeche". Como afirma Campos,

[...] en el Yucatán de la primera república federal, como en general aconteció en México, el modelo gaditano de votaciones indirectas y de ciudadanía ampliada se adoptó con algunas modificaciones, pero el constitucionalismo yucateco estableció un cambio relevante al distinguir los derechos activos y pasivos de las fuerzas armadas. Este rasgo nos permite examinar con mayor detenimiento los ordenamientos reguladores de acceso a los cargos públicos y los conflictos electorales para explicar los intereses de los militares al aliarse con los marginados del poder, derrocar a sus rivales, destruir el sistema federal en la Península y buscar una nueva gobernabilidad con una amplia participación y representación militar". 20

De esta manera el autor explora el papel de los militares como "agentes de presión electoral" en un contexto regional marcado por el conflicto faccional. El artículo ofrece un análisis del papel que desempeñaron los militares en los primeros procesos electorales. El Congreso constituyente de Yucatán

[...] suprimió la abolición del fuero, luego surgió el proyecto de conceder sólo el voto pasivo a los aforados originarios de Yucatán. En febrero de 1825, el rumor de 'quedar sin voto activo ni pasivo en las elecciones populares' para representantes ante el Congreso de la República provocó un 'disgusto general' entre los militares, toda

20 Campos García, "Faccionalismo y votaciones en Yucatán” (201), 2001, p. 61. 
vez que la Constitución federal les concedía el derecho a 'votar y ser votados', a excepción de los comandantes generales. ${ }^{21}$

Los legisladores estatales estaban preocupados por la constante injerencia militar en las votaciones.

La preocupación por el presente es evidente en otro artículo publicado tres años más tarde por Luis Anaya Merchant. ${ }^{22}$ Conforme avanzó el proceso de transición a la democracia en el país, las instituciones representativas recibieron cada vez más atención. Se volvió evidente que el autoritarismo había logrado anclar su poder político a través de un diseño institucional peculiar. Así, ciertos rasgos del sistema político comenzaron a parecer anómalos en el nuevo contexto democrático. Uno de los más notables era la no reelección consecutiva de los legisladores. La reelección de los representantes es una de las piedras de toque de la rendición de cuentas democrática. Desde el punto de vista histórico se volvió importante explorar las tensiones "entre los principios revolucionarios y los derechos ciudadanos”. El artículo estudia la desaparición de la reelección en 1933 y el intento fallido por restaurarla en 1964. El propósito es explicar "la formación histórica de un tabú político". La reforma para eliminar la reelección a la presidencia, que se produjo como una reacción al magnicidio de Álvaro Obregón, también “introdujo un elemento novedoso al negar la reelección para el periodo inmediato posterior a diputados, senadores y ayuntamientos". ${ }^{23}$ La no reelección inmediata de los legisladores promovió una mayor centralización de los mecanismos de selección de los candidatos en el PNR y una mayor disciplina "a las normas formales

21 Campos García, “Faccionalismo y votaciones en Yucatán” (201), 2001, p. 70.

22 Anaya Merchant, “Experiencias políticas e imaginarios sociales” (214), 2004, pp. 365-403.

23 Anaya Merchant, "Experiencias políticas e imaginarios sociales” (214), 2004, pp. 365-403, esp. p. 377. 
e informales del partido y a las decisiones de sus líderes” ${ }^{24} \mathrm{El}$ autor afirmaba que, "con más de 60 años de experiencia antirreeleccionista podemos concluir que el Congreso mexicano ha sido desgastado por excesos de disciplina partidaria oficialista y oposicionista". ${ }^{25}$ En un contexto de competencia pluralista efectiva, como el que ya existía en 2004, la ausencia de reelección inmediata era disfuncional para el régimen democrático, pues impedía que las elecciones sirvieran como un eficaz medio para la rendición de cuentas. Así, el autor proponía que,

[...] la reciente normalización de la vida democrática en el país, plantea la posibilidad de proponer temas tradicionalmente prohibidos [...] La sociedad mexicana ha madurado lo suficiente para debatir el tema de la reelección y las múltiples formas y acotaciones bajo las que la recuperación de este derecho ciudadano democrático podría introducir cambios pertinentes en las instituciones del país. ${ }^{26}$

Diez años después finalmente se reformó la constitución para establecer la reelección de legisladores y presidentes municipales. A partir de entonces, los senadores pueden ser electos hasta por dos periodos consecutivos y los diputados hasta por cuatro.

En la segunda década del siglo xxi se publicaron en $H M$ tres artículos que analizaron las elecciones decimonónicas. Abonaron así al creciente campo de estudio de las prácticas electorales en el siglo XIx en México. En primer lugar, Michael Thomas Ducey exploró los procesos electorales de la insurgencia. ${ }^{27}$ Este artículo es ya una muestra de las nuevas formas de mirar la

${ }^{24}$ Anaya Merchant, "Experiencias políticas e imaginarios sociales” (214), 2004, p. 386.

25 Anaya Merchant, "Experiencias políticas e imaginarios sociales" (214), 2004, p. 396.

26 Anaya Merchant, "Experiencias políticas e imaginarios sociales" (214), 2004, p. 400.

27 Ducey, “Gobierno, legitimidad y movilización” (272), 2019, pp. 1593-1638. 
historia electoral. ¿Cuáles fueron los usos de las elecciones en los territorios ocupados por las fuerzas rebeldes en la Nueva España durante 1813 ? La realización de elecciones en aquel momento parecería poco lógica, como consignan algunos autores de la época. Morelos y sus fuerzas tenían muchas otras preocupaciones más urgentes que llevar a cabo comicios. La violencia y una epidemia de tifo azotaban la región. Como señala el autor: "la última cosa que necesitaban en aquel momento era la competencia entre facciones que conllevaban las votaciones". ¿Por qué, dados los retos que enfrentaban los administradores insurgentes, como la carestía, las epidemias y, sobre todo, la guerra, decidieron "gastar sus energías y cortos recursos en organizar estos ejercicios en la política?”. ${ }^{28}$

¿Para qué sirven las elecciones? ¿Qué esperaban los insurgentes de los procesos electorales? La respuesta está, propone Ducey, en las oportunidades que estos procesos ofrecieron a los liderazgos locales en medio de la "guerra, la peste y el desorden generalizado". La administración de los comicios le dio a la autoridad rebelde la oportunidad de hacerse presente en los poblados más apartados. De la misma manera, "las elecciones hicieron palpable para los residentes rurales del país el funcionamiento de un gobierno superior afiliado a la insurgencia". ${ }^{29}$ Las elecciones sirvieron para movilizar actores, legitimar funcionarios y hacer proselitismo. De esta forma, los procesos electorales insurgentes promovieron nuevas identidades aprovechando "las antiguas instituciones corporativas en la creación de una nueva soberanía". Paradójicamente, todo esto se hizo manteniendo un apego a las formas corporativas del antiguo régimen. A pesar de este carácter conservador y tradicionalista esos experimentos significaron una innegable radicalización de la tradición juntista iniciada en el mundo hispánico en 1808. Así,

28 Ducey, “Gobierno, legitimidad y movilización” (272), 2019, p. 1595.

29 Ducey, "Gobierno, legitimidad y movilización” (272), 2019, p. 1601. 
"los insurgentes tomaron acciones radicales respetando formas conservadoras". Echaron mano de las tradiciones reales y de las repúblicas de indios para vincular los movimientos locales al nuevo congreso nacional.

Dos artículos publicados en 2011 se ocuparon de las elecciones en la primera mitad del siglo xix. En el primero, Juan Cáceres Muñoz estudia las elecciones en Querétaro. ${ }^{30} \mathrm{El}$ texto se inscribe en lo que el autor concibe como la "nueva historia política”. El autor hace un análisis de las dinámicas de poder locales, en particular rastrea el comportamiento del grupo social dominante en la región. Identifica un patrón secular de continuidad: "la cohesión y los privilegios que el grupo detentaba en el siglo xviII se mantuvieron a pesar del nuevo escenario político emergente con la independencia y las ideas liberales". 31 El artículo explora la manera en que la élite empleó los nuevos mecanismos de representación, las elecciones, para mantener su poder. Las dinámicas puestas en marcha por la independencia representaron retos complejos al grupo, que debió adaptarse a las nuevas condiciones. El artículo muestra cómo la participación popular inicial fue controlada y canalizada de tal forma que no representara una amenaza. Así, el análisis "muestra una primera etapa de votación popular que se caracterizó por el 'acarreo' de la gente común; campesinos y jornaleros eran llevados a los lugares de votación por sus propios patrones o capataces con las papeletas de votación preparadas de antemano con el nombre de las personas que se quería favorecer" ${ }^{32}$ La élite adoptó un gatopardismo político. Las amenazas a su posición política hicieron que se cohesionara. Las elecciones permanecieron bajo el firme control notabiliar y fueron empleadas para asegurar su posición de preeminencia. Cabe señalar que, contra lo que señala el autor,

30 CÁceres Muñoz, “Entre la libertad y los privilegios” (242), 2011, pp. 477-530.

31 CÁceres Muñoz, "Entre la libertad y los privilegios” (242), 2011, p. 480.

32 CÁceres Muñoz, “Entre la libertad y los privilegios” (242), 2011, p. 518. 
esto no era una “falsa fachada liberal y democrática” para cuidar el poder y los privilegios. Querétaro ilustra un patrón que va más allá de México y que incluye al mundo occidental. El principio de "distinción" es constitutivo del gobierno representativo. Es decir, los representantes debían ser diferentes de los electores y superiores a ellos. ${ }^{33}$

El segundo artículo de ese año estuvo a cargo de quien esto escribe. ${ }^{34}$ En él se estudian la Convocatoria, las elecciones y el congreso extraordinario de 1846. Estas experiencias, a pesar de su importancia, no sólo para la historia política y electoral de México sino del mundo, no habían recibido suficiente atención por parte de los historiadores. Lo notable es que a mitad del siglo XIX se inventó un original sistema electoral, sin precedentes, que reemplazó al individuo por las clases sociales como sujeto a representar. No sólo se concibió este método, sino que en vísperas de la guerra con Estados Unidos se puso en práctica en una parte significativa del país. De las elecciones de ese año emergió un congreso constituyente de escasa vida.

Finalmente, un ejemplo poco usual de análisis de las elecciones posrevolucionarias es el artículo de Javier MacGregor Campuzano, "Elecciones federales y transición a un nuevo régimen: Mexico, 1920 y 1922. Estudios de caso", publicado en 2010. ${ }^{35} \mathrm{El}$ autor se adentra en un terreno poco explorado: las elecciones y la representación política en los años veinte y treinta del siglo xx. La actividad parlamentaria del periodo presenta algunos enigmas. Por ejemplo, entre 1920 y 1922 más del 80\% de las iniciativas aprobadas por la cámara baja fueron presentadas por diputados y no por el Ejecutivo. El artículo estudia dos coyunturas electorales

33 Véase Manin, Los principios.

34 Aguilar Rivera, "La convocatoria, las elecciones y el Congreso” (242), 2011, pp. 531-588.

35 MacGregor Campuzano, “Elecciones federales y transición” (238), 2010, pp. 1119-1174. 
[...] que muestran los mecanismos formales por los que transitó el proceso político electoral inmediatamente después de la caída de Carranza y el triunfo de los sonorenses en mayo de 1920. El primero presenta un caso en el que los comicios se realizaron ajustando el calendario electoral al momento de cambio político violento que se acababa de vivir y muestran claramente la transición hacia el nuevo régimen; el segundo analiza el proceso de consolidación por el que el gobierno busca el restablecimiento institucional del proceso electoral como mecanismo de legitimación política.

En ese periodo se sentó el precedente de que "los procesos electorales en el plano federal -cualquiera que fuera su característica-, no dejaron de realizarse puntualmente en lo porvenir". Como señala el autor, éste no fue un logro menor. El análisis de las elecciones documenta la competencia y el incipiente pluralismo en los albores del régimen posrevolucionario. La activa participación de los políticos y de los partidos más prominentes de la época en el congreso indica que ésos eran ámbitos importantes y significativos. Aunque la política "bronca” que involucraba la violencia no estuvo ausente, una parte de la participación fue canalizada, “al menos de manera parcial”, por medios institucionales. Así, las elecciones de 1920 "muestran la preocupación de un régimen que proviene de la deposición de un gobierno constitucional por reconstruir, a partir de este instrumento político, una base de legitimación que, entre muchas otras herramientas, le permita una consolidación paulatina, pero firme". ${ }^{36}$

Este breve recuento de la forma en que se han analizado las elecciones y el sistema político en $H M$ da cuenta no sólo de los cambiantes enfoques y perspectivas historiográficos, sino de las mutaciones políticas que el país ha experimentado. Las elecciones nacieron antes que la nación y muchísimo antes que

\footnotetext{
36 MacGregor Campuzano, "Elecciones federales y transición” (238), 2010, p. 1170.
} 
la democracia, pero son, paradójicamente, artefactos novísimos en nuestra vida nacional. El presente de competencia pluralista nos ha hecho volver la mirada al abultado expediente del pasado electoral. Donde antes veíamos formas huecas ahora vemos prácticas sociales y políticas que necesitan ser explicadas. Faltan por descubrirse muchos territorios de ese valiente mundo nuevo.

\section{REFERENCIAS}

Aguilar Rivera, José Antonio (coord.), Las elecciones y el gobierno representativo en México (1810-1910), México, Fondo de Cultura Económica, Instituto Federal Electoral, Consejo Nacional para la Cultura y las Artes, Consejo Nacional de Ciencia y Tecnología, 2010.

Annino, Antonio (coord.), Historia de las elecciones en Iberoamérica, siglo XIX, Buenos Aires, Fondo de Cultura Económica, 1995.

Cazar, María Amparo e Ignacio Marván (coords.), Gobernar sin mayoría, México, Centro de Investigación y Docencia Económicas, Taurus, 2002.

Emmerich, Gustavo Ernesto, “Las elecciones en México, 1808-1911: sufragio efectivo, ¿no reelección?”, en González Casanova (ed.), 1985, pp. 41-68.

GaNTús, Fausta (coord.), Elecciones en el México del siglo XIX: las prácticas, México, Instituto Mora, 2016, 2 volúmenes.

Gantús, Fausta y Alicia Salmerón (coords.), Contribución a un diálogo abierto. Cinco ensayos de historia electoral latinoamericana, México, Instituto Mora, 2016.

Gantús, Fausta y Alicia Salmerón (coords.), Prensa y elecciones: formas de hacer política en el México del siglo XIX, México, Instituto Mora, Consejo Nacional de Ciencia y Tecnología, Instituto Federal Electoral, 2014.

GanTús, Fausta (coord.), Elecciones en el México del siglo XIX: las fuentes, México, Instituto Mora, 2015.

González Casanova, Pablo (ed.), Las elecciones en México: evolución y perspectivas, México, Siglo Veintiuno Editores, 1985. 
José, Georgette (coord.), Candidatos, campañas y elecciones presidenciales en México. De la República Restaurada al México de la alternancia (18762006), México, Universidad Nacional Autónoma de México, 2012.

Manin, Bernard, Los principios del gobierno representativo, Madrid, Alianza Editorial, 1998.

ReInA, Leticia, Cultura politica y formas de representación indígena en México, siglo XIX, México, Instituto Nacional de Antropología e Historia, 2015. 
